\title{
BMJ Global Health Elements of a strategic approach for strengthening national mortality statistics programmes
}

\author{
Chalapati Rao
}

To cite: Rao C. Elements of a strategic approach for strengthening national mortality statistics programmes. BMJ Global Health 2019;4:e001810. doi:10.1136/ bmjgh-2019-001810

Handling editor Seye Abimbola

Received 2 July 2019

Revised 3 September 2019

Accepted 21 September 2019

Check for updates

(c) Author(s) (or their employer(s)) 2019. Re-use permitted under CC BY-NC. No commercial re-use. See rights and permissions. Published by BMJ.

Department of Global Health, Research School of Population Health, Australian National University College of Medicine Biology and Environment, Canberra, Australian Capital Territory, Australia

Correspondence to

Dr Chalapati Rao

chalapati.rao@anu.edu.au

\section{ABSTRACT}

Information on cause-specific mortality from civil registration and vital statistics (CRVS) systems is essential for health policy and epidemiological research. Currently, there are critical gaps in the international availability of timely and reliable mortality data, which limits planned progress towards the UN Sustainable Development Goals. This article describes an evidence-based strategic approach for strengthening mortality data from CRVS systems. National mortality data availability scores from the Global Burden of Disease study were used to group countries into those with adequate, partial or negligible mortality data. These were further categorised by geographical region and population size, which showed that there were shortcomings in availability of mortality data in approximately two-thirds of all countries. Existing frameworks for evaluating design and functional status of mortality components of CRVS systems were reviewed to identify themes and topics for assessment. Detailed national programme assessments can be used to investigate systemic issues that are likely to affect death reporting, cause of death ascertainment and data management. Assessment findings can guide interventions to strengthen system performance. The strategic national approach should be customised according to data availability and population size and supported by human and institutional capacity building. Countries with larger populations should use an incremental sampling approach to strengthen CRVS systems and use interim data for mortality estimation. Periodic data quality evaluation is required to monitor system performance and scale up interventions. A comprehensive implementation and operations research programme should be concurrently launched to evaluate the feasibility, success and sustainability of system strengthening activities.

\section{INTRODUCTION}

Planned progress towards achieving good health and well-being at all ages as articulated in the United Nations Sustainable Development Goals (UNSDGs) requires timely and reliable epidemiological data. ${ }^{1}$ At the population level, premature mortality accounts for approximately two-thirds to three-fourths of the national burden of disease across the world, with developing countries experiencing
Summary box

- Timely and reliable national cause-specific mortality statistics are necessary for evidence-based health policy and monitoring progress towards the UN Sustainable Development Goals.

- There are gaps in mortality data availability from national civil registration and vital statistics (CRVS) systems in all regions of the world.

- A detailed national CRVS systems assessment and data quality evaluation according to a standard framework is essential to identify limitations in death registration and data compilation.

- The assessment findings should be the basis for a comprehensive strategy to strengthen mortality statistics programmes.

- The strategy should emphasise capacity building as well as implementation and operations research to evaluate the feasibility, success and sustainability of the system strengthening programme.

higher levels of premature mortality. Hence, there is a need for accurate data on deaths by age, sex and cause, ideally from national civil registration and vital statistics (CRVS) systems, which are the optimal source for such data. ${ }^{2}$ However, there is a critical paucity in the availability of reliable mortality data from most developing countries, owing to dysfunctional CRVS systems. ${ }^{3}$

While this gap in data availability has been well known, there has been little progress over the past five decades. CRVS development initiatives were initially launched in the 1960 s, in a series of model birth and death registration projects in developing countries across Asia, the Middle East, Africa and South America. ${ }^{4}$ However, these demonstration projects did not translate into organised system strengthening activities at country level..$^{5}$ This was followed up by a range of CRVS development activities coordinated by the United States Centers for Disease Control and the United Nations Statistics Division (UNSD) over the next three decades, leading to the 
publication of a series of technical manuals on design and operational aspects of CRVS systems. ${ }^{67}$ Around the turn of the century, international population health assessments such as the Global Burden of Disease (GBD) analyses as well as the United Nations Millennium Development Goals programme brought into sharp focus the need for timely and reliable data for accurate measurement of levels and trends in mortality. ${ }^{89}$ The absence of detailed mortality data necessitated the use of extensive modelling strategies based on a bare minimum set of data inputs to estimate mortality and burden of disease for many developing countries. ${ }^{10}$

In recognition of the limitations of statistical modelling, an international scientific collaboration published a manuscript series in 2007 that highlighted the gaps in data availability and quality and also recommended a potential way forward to improve empirical data. ${ }^{11}$ This also coincided with research to develop international standards for household interview methods known as 'verbal autopsies' (VA), to ascertain causes for deaths that occur in the absence of medical attention. ${ }^{12}$ Most recently, CRVS systems have received enhanced international attention to assist with good governance and health policy, in conjunction with the UNSDGs for 2030. The renewed interests in CRVS have been articulated in initiatives launched by the World Bank, UNSD, WHO, the United Nations Economic Commissions for the African and Asia-Pacific regions and other international partnerships. ${ }^{13-19}$ These announcements include calls for scaling up investments as well as better coordination between interest groups, donors and countries, within an implementation time frame between 2015 and 2030. Initiatives have also been undertaken to develop toolkits for review and assessment of CRVS systems, training materials and regional action frameworks for implementation. ${ }^{20-25}$ This article proposes a strategic approach to apply these and other materials in comprehensive mortality statistics strengthening programmes customised to the national context of existing CRVS systems and data availability. The article also describes an implementation and operations research framework for conducting specific activities as a starting point for national CRVS development strategies.

\section{DATA NEEDS}

For health sector purposes, CRVS systems are a natural data source for information on deaths and causes of death. However, the absence of clear community incentives for death registration, coupled with the challenges in cause of death ascertainment result in these aspects of CRVS being largely neglected. This has changed recently, with the UNSDGs 2015-2030, along with the WHO's General Programme of Work 13 for 2019-2023 (WHO GPW 13) raising the critical importance of the need to measure cause-specific mortality from a broad range of health conditions. ${ }^{126}$ Table 1 lists the key health categories and related causes of death along with statistical targets that need to be measured and monitored on a regular basis. While the previous set of targets under the UN Millennium Development Goals focused on a limited set of causes related to maternal and child health as well as the three major infectious diseases (HIV, malaria and tuberculosis), the current causes of interest include this set and also covers a broader range of causes including major non-communicable diseases as well as deaths from road traffic injuries, natural disasters and exposure to hazardous chemicals. Even for child health, the focus on neonatal mortality has sharpened the need for careful measurement of stillbirths, prematurity, low birth weight, birth asphyxia and other perinatal conditions.

The expanded cause list also includes diseases resulting from air pollution, unsafe water and soil contamination and other viral and climate sensitive infections. In addition, the WHO GPW13 has listed the need to reduce suicide mortality rates as a tracer condition to monitor improvements in mental health. Other conditions that are not mentioned in these targets but are also important from clinical and public health perspectives include chronic kidney disease, liver diseases and dementia, which are increasing in magnitude across the world. Clearly, this broad spectrum of diseases of interest can be best measured by monitoring population level mortality and causes of death through CRVS systems, rather than alternative sources such as sample surveys or disease surveillance programmes. ${ }^{27}{ }^{28}$ Further, death registration should also include accurate cause attribution supported by mechanisms for disease coding and classification according to the Tenth Revision of the International Classification of Diseases and Health Related Problems (ICD-10).$^{29}$ However, only a fraction of the world's countries have efficient CRVS systems that generate routine and reliable mortality statistics by age, sex and cause. An understanding of the levels and distribution of problems with data availability is essential to design a strategic approach to address these challenges.

\section{DATA AVAILABILITY}

Table 2 shows that there are problems with mortality data availability and quality across all regions as defined by the WHO ${ }^{30}$ Data availability is defined by an indicator named 'per cent well-certified' which is the estimated proportion of deaths from national CRVS systems that can be used for measuring the burden of disease in a population. This indicator was developed and calculated for each country by the GBD Study Team. ${ }^{31}$ It is calculated by multiplying the proportion of deaths in a population that are estimated to have been actually reported in a year (termed as completeness) with the proportion of these reported deaths that are considered to be 'well certified' as to the cause of death (defined as the complement of the proportion of deaths with ill-defined causes). As a general rule, the lower the data availability score, the more extensive would be the data modelling approach used to derive national 
Table 1 Mortality indicators and targets for the UNSDGs for 2030 and WHO GPW 13 (2019-2023)

\begin{tabular}{|c|c|c|}
\hline Health category & Major causes of death & UNSDG targets to be achieved by 2030 \\
\hline Maternal health & $\begin{array}{l}\text { Maternal causes - haemorrhage, } \\
\text { obstructed labour, hypertensive } \\
\text { disorders, sepsis, abortion }\end{array}$ & $\begin{array}{l}\text { Reduce global Maternal Mortality Ratio } \\
\text { (MMR) to }<70 / 100000 \text { births }\end{array}$ \\
\hline Child health & $\begin{array}{l}\text { Prematurity, birth asphyxia, } \\
\text { hypothermia } \\
\text { Diarrhoea, pneumonia, malaria, sepsis } \\
\text { Congenital anomalies }\end{array}$ & $\begin{array}{l}\text { Reduce neonatal mortality rate to } 12 / 1000 \\
\text { live births } \\
\text { Reduce under- } 5 \text { mortality to } 25 / 1000\end{array}$ \\
\hline Infectious diseases & $\begin{array}{l}\text { HIV, tuberculosis, malaria } \\
\text { Hepatitis B and C }\end{array}$ & $\begin{array}{l}\text { Reduce malaria/Tuberculosis deaths by } \\
50 \% \text { by } 2023^{*} \\
\text { Reduce Hep B/Hep C deaths by } 40 \% \text { by } \\
2023^{*}\end{array}$ \\
\hline Non-communicable diseases & $\begin{array}{l}\text { Cancers } \\
\text { Cardiovascular diseases } \\
\text { Chronic obstructive lung disease } \\
\text { Diabetes }\end{array}$ & $\begin{array}{l}\text { Reduce risk of mortality between ages } 30 \\
\text { and } 70 \text { years from these four conditions by } \\
33 \%\end{array}$ \\
\hline Mental health & - Suicide & $\begin{array}{l}\text { Reduce suicide mortality rate by } 15 \% \text { by } \\
2023^{*}\end{array}$ \\
\hline Injuries & - Road traffic injuries & Reduce death rate by $50 \%$ \\
\hline Ambient and household air pollution & $\begin{array}{l}\text { Lower respiratory infections } \\
\text { Chronic obstructive lung disease } \\
\text { Lung cancer } \\
\text { Stroke/lschaemic heart disease }\end{array}$ & Substantial reduction in mortality rates \\
\hline $\begin{array}{l}\text { Unsafe water, sanitation and lack of } \\
\text { hygiene }\end{array}$ & Diarrhoeal diseases & $\begin{array}{l}\text { Reduce number of deaths from water and } \\
\text { soil contamination }\end{array}$ \\
\hline Hazardous chemicals & - Unintentional poisoning & Reduce number of deaths \\
\hline Climate change/disasters & - Injuries/missing persons & Reduce death rates \\
\hline Climate sensitive diseases & $\begin{array}{l}\text { Diarrhoeal diseases, leishmaniasis, } \\
\text { malaria, trypanosomiasis, } \\
\text { schistosomiasis, dengue }\end{array}$ & Reduce mortality rates by $10 \%$ by 2023 \\
\hline
\end{tabular}

${ }^{*}$ Specified by the WHO GPW for 2019-2023. ${ }^{26}$

GPW, General Programme of Work; UNSDG, UN Sustainable Development Goal.

mortality estimates and the associated uncertainty with these estimates.

Per cent well certified $=$ completeness $(\%) *(1-\%$ ill-defined).

The methods for measurement of completeness as well as proportions of deaths assigned ill-defined causes are complex, and dealt with in detail elsewhere. ${ }^{32} 33$ The national 'per cent well certified' scores also take into account additional factors including adjustments for coverage and representativeness of subnational data (where national CRVS data are not available), and adjustments for use of VA methods for determining causes of death. ${ }^{31}$ For the analyses reported in table 2, the specific national scores from the GBD study team for $2016^{31}$ were used to group countries with negligible $(0 \%-34 \%)$, partial $(35 \%-84 \%)$ or adequate $(>85 \%)$ data. These categories were further grouped according to geographical location and national population size to help understand the magnitude and distribution of problems with data availability. Table 2 shows that about $40 \%$ of countries across the world have a 'negligible' data rating, and these are mostly concentrated in Africa and the Western Pacific Region. The Eastern Mediterranean and South East Asian regions also have many countries with 'negligible' data, and without a single country having adequate data.

More importantly, the 'partial' data ratings for four countries with very large populations-China, India, Indonesia and Bangladesh-are actually based on nationally representative sample registration systems, which cover only a small fraction $(<10 \%)$ of their national populations. These countries also employ VA methods to ascertain causes of death within their sample population clusters, which adds to the overall uncertainty in data quality. Hence, these countries could also be potentially classified to the 'negligible' category, which would result in a total of about 5 billion $(65 \%)$ out of the estimated world's population of 7.7 billion in 2019 residing in countries that lack data for reliably estimating population level cause-specific mortality. This alarming situation calls for urgent remediation.

Countries in the European and American regions mostly operate national CRVS systems, but almost half 
Table 2 Distribution of countries by mortality data quality rating* according to geography and population size

\begin{tabular}{|c|c|c|c|c|c|}
\hline \multirow[b]{2}{*}{ WHO region† } & \multirow[b]{2}{*}{ Population } & \multicolumn{3}{|c|}{ Data quality rating } & \multirow[b]{2}{*}{ Total } \\
\hline & & Negligible & Partial & Adequate & \\
\hline \multicolumn{6}{|l|}{ Africa } \\
\hline & $<10 m$ & 16 & 2 & 1 & 19 \\
\hline & $10-50 m$ & 22 & 0 & 0 & 22 \\
\hline & $>50 \mathrm{~m}$ & 4 & 2 & 0 & 6 \\
\hline \multicolumn{6}{|l|}{ Americas } \\
\hline & $<10 m$ & 1 & 16 & 5 & 22 \\
\hline & $10-50 m$ & 2 & 5 & 5 & 12 \\
\hline & $>50 \mathrm{~m}$ & 0 & 1 & 3 & 4 \\
\hline \multicolumn{6}{|c|}{ Eastern Mediterranean } \\
\hline & $<10 m$ & 6 & 2 & 0 & 8 \\
\hline & $10-50 m$ & 8 & 3 & 0 & 11 \\
\hline & $>50 \mathrm{~m}$ & 1 & 2 & 0 & 3 \\
\hline \multicolumn{6}{|l|}{ Europe } \\
\hline & $<10 m$ & 3 & 13 & 16 & 32 \\
\hline & $10-50 m$ & 1 & 8 & 5 & 14 \\
\hline & $>50 \mathrm{~m}$ & 0 & 3 & 3 & 6 \\
\hline \multicolumn{6}{|l|}{ South east Asia } \\
\hline & $<10 m$ & 2 & 1 & 0 & 3 \\
\hline & $10-50 m$ & 2 & 1 & 0 & 3 \\
\hline & $>50 \mathrm{~m}$ & 1 & 4 & 0 & 5 \\
\hline \multicolumn{6}{|l|}{ Western Pacific } \\
\hline & $<10 m$ & 10 & 4 & 2 & 16 \\
\hline & $10-50 m$ & 2 & 1 & 1 & 4 \\
\hline & $>50 \mathrm{~m}$ & 1 & 4 & 0 & 5 \\
\hline \multicolumn{6}{|l|}{ World } \\
\hline & $<10 m$ & 38 & 38 & 24 & 100 \\
\hline & $10-50 m$ & 37 & 18 & 11 & 66 \\
\hline & $>50 \mathrm{~m}$ & 7 & 16 & 6 & 29 \\
\hline Total & & 82 & 72 & 41 & 195 \\
\hline
\end{tabular}

*Based on 'percentage of well certified' data; Negligible=0\%-34\%; Partial=35-84\%; Adequate $=85 \%+{ }^{31}$

†For list of countries in WHO regions, see Ref. 30.

of them have problems with either data completeness or quality of cause attribution or both, illustrating the global nature of mortality data deficiencies. Also, in countries with a partial data rating, there could be subnational variations in data availability by geography or between urban and rural areas. For instance, analysis of data from Brazil identified lower data quality in northern regions as compared with southern regions, necessitating specific interventions to improve data quality in the northern regions. ${ }^{34}{ }^{35}$ In summary, there is a need for a detailed assessment of the CRVS systemic gaps and weaknesses that result in limitations in data availability and quality, including subnational analysis where applicable, as a basis for targeted system strengthening interventions.

\section{CRVS ASSESSMENT}

As could be understood from the complexity of the indicator definition in representing mortality data quality in a single measure, it is probable that there could be several aspects of the national mortality statistics programme that require simultaneous strengthening interventions. For instance, a low score could be a result of problems with one or more of death notification practices, organisation of registration services, assignment of causes of death or with protocols for data management and analysis. The UNSD has published a detailed framework for CRVS systems assessment that addresses all these aspects. ${ }^{25}$ There are other frameworks which partially cover different elements of the UNSD framework, ${ }^{20} 36$ and examples of regional and country-specific assessments with recommendations for 
Table 3 CRVS assessment themes, topics and outputs

\begin{tabular}{|c|c|c|}
\hline Themes & Topics for assessment & Assessment outputs \\
\hline \multicolumn{3}{|c|}{ Civil registration and data capture } \\
\hline CRVS administration & $\begin{array}{l}\text { CRVS legal framework } \\
\text { CRVS structure and organisation }\end{array}$ & $\begin{array}{l}\text { Definitions of vital events, residents, notifiers, } \\
\text { reporting periods } \\
\text { Lead/support institutions for registration and vital } \\
\text { statistics } \\
\text { - Institutional responsibilities and reporting relationships }\end{array}$ \\
\hline $\begin{array}{l}\text { CRVS business } \\
\text { processes }\end{array}$ & $\begin{array}{l}\text { Mechanisms for recording vital events } \\
\text { Specific institutional/personnel roles }\end{array}$ & $\begin{array}{l}\text { Rules and procedures for notification/registration } \\
\text { Notification forms/ registers/civil status certificates } \\
\text { Mapped sequence of registration activities and } \\
\text { information flow }\end{array}$ \\
\hline $\begin{array}{l}\text { Cause of death } \\
\text { ascertainment }\end{array}$ & $\begin{array}{l}\text { Forms, questionnaires and protocols } \\
\text { Data standards for statistics }\end{array}$ & $\begin{array}{l}\text { Medical certification/verbal autopsy instruments and } \\
\text { manuals } \\
\text { Protocols for coronial/forensic review for unnatural } \\
\text { deaths } \\
\text { Coding and classification schemes for causes of } \\
\text { death }\end{array}$ \\
\hline
\end{tabular}

\begin{tabular}{|c|c|c|}
\hline $\begin{array}{l}\text { Data processing and } \\
\text { management }\end{array}$ & $\begin{array}{l}\text { Mechanisms for data compilation } \\
\text { Protocols for monitoring and quality } \\
\text { control }\end{array}$ & $\begin{array}{l}\text { Electronic databases and instructions for } \\
\text { computerisation } \\
\text { Facilities for data archival and transmission } \\
\text { Guidelines for monitoring for reporting timeliness and } \\
\text { accuracy }\end{array}$ \\
\hline Quality evaluation & $\begin{array}{l}\text { Evaluation of secondary data } \\
\text { Field operations research }\end{array}$ & $\begin{array}{l}\text { Data plausibility assessment } \\
\text { Estimation of proportion of reported deaths } \\
\text { (completeness) } \\
\text { Cause of death validation (percentage 'well-certified') }\end{array}$ \\
\hline Data utilisation & $\begin{array}{l}\text { - Analysis of outcome indicators } \\
\text { - Policy analysis }\end{array}$ & $\begin{array}{l}\text { Demographic mortality indicators } \\
\text { Epidemiological analysis of causes of death } \\
\text { - Burden of disease/cost effectiveness analysis }\end{array}$ \\
\hline
\end{tabular}

CRVS, civil registration and vital statistics.

interventions to strengthen quality assurance and quality control of CRVS systems. ${ }^{37-43}$

Table 3 describes the themes and topics for assessing CRVS and the specific outcomes from the assessment or from related follow-up activities. Most countries have a basic registration framework including a law and administrative process for registering births and deaths. These should be assessed for adequacy of definitions of vital events and reporting periods for notification, and for specification of organisations and personnel responsible for CRVS operations. ${ }^{28}$ For larger countries ( $>50$ million), the assessment should identify whether the CRVS organisation is based on a centralised or decentralised model (defined in Ref. 25), which will guide recommendations for changes to specific system attributes. The review should map the business processes linking institutions and activities in conducting registration and in enabling information flow, as depicted in examples from Viet Nam and the Indian state of Punjab. ${ }^{39}$ Registration forms for births and deaths should be checked for inclusion of prescribed essential variables, ${ }^{28}$ For accurate causes of death, the system should adopt the medical death certificate for hospital deaths, VA questionnaires for community deaths, and coding and classification standards prescribed by the WHO. ${ }^{29} 4445$ The assessment should review the CRVS quality assurance protocol for regular supervision and performance monitoring of registration units and for periodic internal audits of infrastructure and human resources. Findings from the assessment can guide interventions to strengthen the legal framework, nominate appropriate institutions and personnel for specific tasks, develop optimal registration forms and procedures, and help mobilise required infrastructure and resources. In general, system strengthening should build on existing models and procedures which will facilitate the overall management of change, from an organisational perspective.

Evaluation of the vital statistics components of CRVS systems is largely summative, based on the availability and quality of data from the system. The availability of good quality mortality statistics as defined by high levels of 'percentage well certified' data $(>85 \%)$ on a timely basis would imply efficient death registration and data management and conversely, lower scores imply problems from one or more aspects. Hence, in addition to the civil registration assessment, countries with 'partial' or 'negligible' data should also undertake a detailed assessment of the vital statistics components, outlined in table 3 . First, there 
should be a review of processes for data compilation, computerisation, transmission and archival as well as of existing procedures for monitoring data timeliness and accuracy. Subsequently, a standard framework should be used to evaluate the completeness, reliability, validity and policy relevance of available mortality and cause of death statistics. ${ }^{46} 47$ Secondary data analysis methods could be used to assess completeness and reliability through comparing observed quality parameters from available data with similar parameters derived for the study population from demographic and epidemiological models. ${ }^{48} 49$ Alternatively, data completeness could be directly evaluated through record linkage mechanisms using two or more data sources on vital events over the same reference period..$^{50}$ The quality of causes of death could be assessed for the proportions assigned codes for ill-defined causes and for plausibility of age-sex patterns by cause. Validity and reliability of causes of death could be directly evaluated through epidemiological studies that compare registered causes of death against information from clinical records, or from household VA interviews. ${ }^{465253}$

Findings from these vital statistics data quality assessments can help locate gaps and weaknesses in data capture, data management and information flow which need to be resolved to improve data quality. ${ }^{39}$ The empirically derived estimates of completeness and patterns of misclassification of causes of death in registration data can be used for statistical adjustments and analyses to derive corrected mortality indicators. ${ }^{35} 5354$ In principle, such local empirically derived mortality indicators have greater practical and political relevance for policy analysis and programme evaluation in national contexts, as compared with indicators reported from global estimation exercises.
THE SYSTEM STRENGTHENING STRATEGY

From an implementation perspective, the system strengthening strategy for each country would need to address one or both of the civil registration and vital statistics components of CRVS systems. The spectrum of data needs, diversity in data availability and range of required interventions for different aspects of CRVS functions described in table 3 indicates the complex challenges in designing system strengthening programmes. A customised national strategy should take into account the data availability score, population size and findings from the CRVS assessment. Interventions would need to be implemented as a package, rather than as individual 'stand-alone' activities, for there to be any real impact on the overall score. Moreover, intervention programmes need to be contextualised to specific attributes and characteristics of national CRVS systems, including those of the administrative, health and social sectors of the country. 3738

Figure 1 depicts a generic scheme for design and implementation of CRVS system strengthening programmes. For countries with 'negligible' data, the initial step would be to conduct a thorough civil registration assessment, along with a review of processes for data compilation. The assessment outcomes should be used to design interventions covering all elements of CRVS in a model programme, to be tested through an implementation research study, either in sentinel sites or in an adequately sized representative sample of population clusters. ${ }^{55} 56$ Data from the implementation model should undergo a detailed quality evaluation and be used to develop estimates of keyvital statisticsindicators. Such implementation

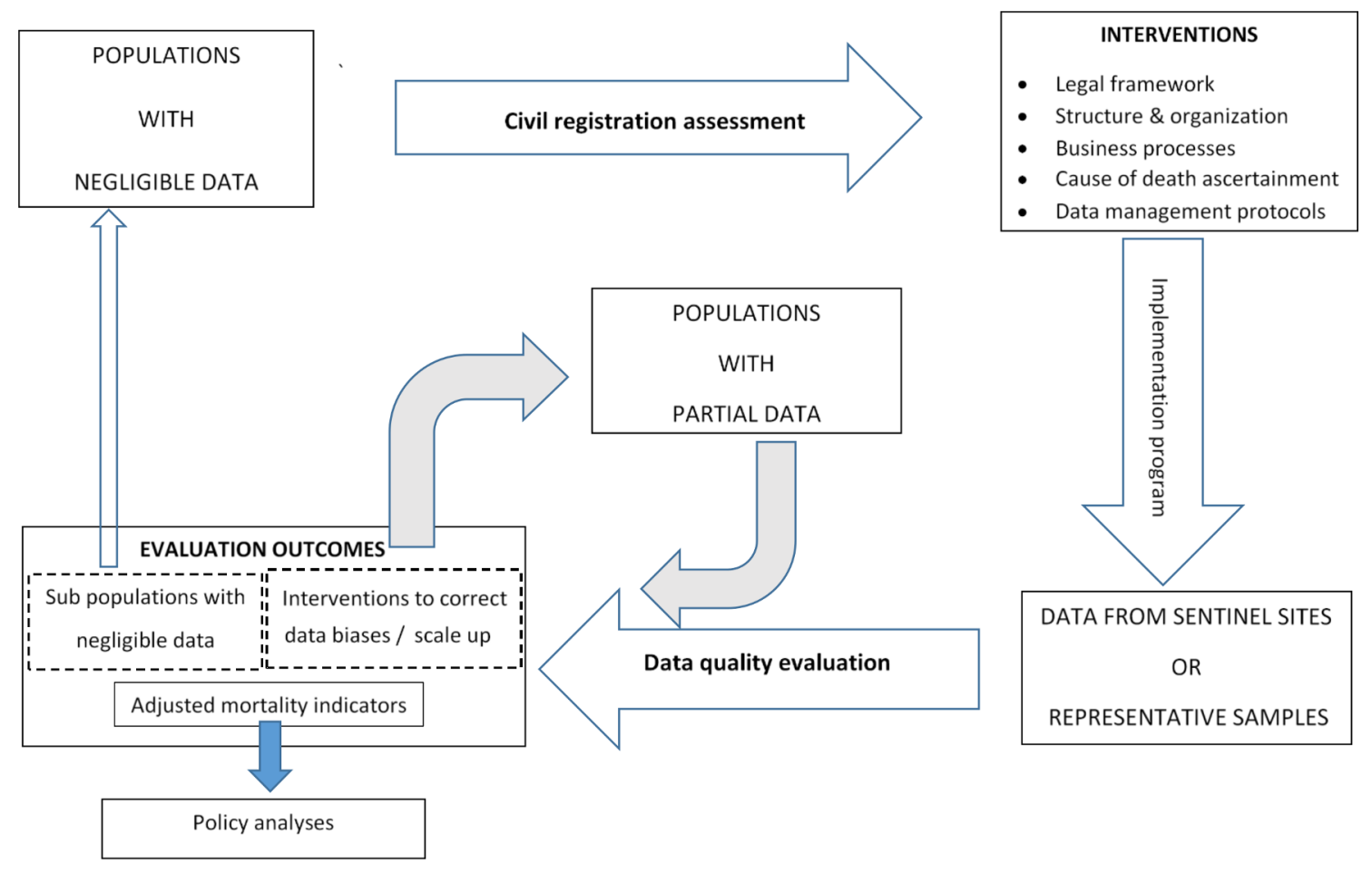

Figure 1 Strategies for national mortality statistics strengthening programmes according to level of data availability. 
research has been successfully conducted in Indonesia and Viet Nam, yielding first ever empirical population based mortality measures for these countries. ${ }^{57-59} \mathrm{It}$ could be possible for countries with populations of less than 10 million to then directly scale up CRVS reforms from pilot implementation studies to national coverage, with appropriate technical leadership and resources. In countries with larger populations ( $>10$ million), the pilot phase could be followed by a legal framework mandating universal CRVS coverage, and an incremental sampling approach for vital statistics programmes. The incremental sampling approach would need to be sustained over 10-20 years for very large populations ( $>50$ million), given the considerable lead time for system strengthening to take effect. This will facilitate uniform implementation of system changes, close monitoring of data quality and utilisation of interim representative data for analysis of mortality indicators. ${ }^{56}$ This approach is exemplified by the experience in China, ${ }^{6061}$ and has now commenced in Indonesia, through its recently established nationally representative Sample Registration System. ${ }^{62}$

Countries with 'partial' data could first undertake a thorough data quality evaluation followed by an operations research study to estimate registration completeness as well as accuracy of causes of death. ${ }^{516364}$ The study outcomes could be used to derive mortality indicator estimates, as achieved in Thailand and Malaysia. ${ }^{53} 54$ Observations from operations research on CRVS weaknesses can guide interventions to strengthen data capture and compilation. The evaluation may also identify subpopulations with negligible data for which a detailed civil registration assessment and implementation programme would be required. Over time, improvements in coverage, completeness and cause attribution will increase the mortality data availability score, and subsequent iterations of data quality evaluation will help monitor progress in CRVS development. Finally, even countries with adequate data availability should periodically undertake CRVS assessments, as exemplified by the routine data evaluation and improvement programmes in Canada and the USA. ${ }^{65} 66$

A key element of the strategy is capacity building for data capture, quality evaluation, analysis and utilisation, as described in detail from experiences in Indonesia. ${ }^{67}$ Training and skill development will be required for staff and professionals who are already in service, and this creates challenges in introducing and managing change in work environments across institutions from different sectors. ${ }^{67}$ Strengthening cause of death certification will require changes to entrenched practices of delegating this task to junior, untrained doctors in hospitals ${ }^{68}$ and updates to medical education curriculum to ensure adequate preservice skill development. ${ }^{69}$ In many countries, training will also cover use of VA methods for community deaths. ${ }^{70}$ From a planning perspective, there is a need to first establish a critical mass of skilled human resources to conduct all aspects of the initial CRVS development research activity, preferably within one institution with a mandated programme leadership role, which could then build additional sub national capacity for scaling up the programme.

Strong technical leadership for mortality statistics programmes could be best enabled through involvement of public health academic institutions throughout the cycle of development activities, and this should be based on a framework for implementation and operations research. Such research is essential to foster a culture of objectivity in these system strengthening activities, to avoid the pitfalls and resultant failures from previous similar initiatives. ${ }^{2} 71$ Implementation programme outcomes could be assessed in terms of their feasibility, success and sustainability. Feasibility could be measured through programme costs, availability of infrastructure and efficiency of the new or revised CRVS business processes. Programme success could be measured through monitoring improvements in data quality, timeliness and utilisation. Sustainability could be understood by evaluating the human resources and institutional capacity established at national and subnational levels as well as by gauging the political support and commitment for CRVS programmes.

\section{CONCLUSION}

In the current environment of data driven policy and management, the limited availability of reliable national mortality statistics is clearly established and widely known, although uniquely presented from geographical, data quality and national population size perspectives in this article. The interventions required to improve data availability, as well as broad strategies for designing CRVS strengthening programmes in different settings have also been described here. However, such development initiatives require adequate political support and commitment of resources across multiple sectors and institutions.

Around four decades ago, an international evaluation suggested that countries paid attention to vital statistics programmes at a stage in their economic development where such data were imperative for policy. ${ }^{72}$ These factors probably influenced improvements in national CRVS systems in Turkey, Oman and the Philippines in recent times. ${ }^{73-75}$ Moreover, the advent of computerisation has vastly enhanced the potential for greater efficiencies in data management. For instance, electronic integration of vital statistics data from parallel collections by the administrative and health sectors enabled rapid improvements in data completeness in Brazil and Iran. ${ }^{34} 76$

While system strengthening programmes can incur capital costs for redesign and implementation research, there is potential for realignment of available local health and administrative resources for such development. In addition, modifications to preservice and in-service training curricula can address several aspects of capacity building, which is a major cost heading. These investments, if based on a strategic approach, have considerable potential for establishing CRVS systems as a key public good for human development. The current economic thrusts for 
globalisation and collective development have created global imperatives and motivation for accurate data for health policy and monitoring progress towards the UNSDGs at all levels. Initiatives based on the CRVS analytical frameworks and system strengthening strategies described in this article could play a decisive role in improving mortality data availability for reliable health measurement and evidence based health action in developing countries.

Contributors CR conducted the review, analysed the data and developed the strategic approach and the conclusions presented in the article.

Funding This study was funded by Department of Foreign Affairs and Trade, Australian Government (70856)

Competing interests None declared.

Patient consent for publication Not required.

Provenance and peer review Not commissioned; externally peer reviewed.

Data availability statement Data relevant to Table 2 are available in a public, open access repository as per Reference 31 .

Open access This is an open access article distributed in accordance with the Creative Commons Attribution Non Commercial (CC BY-NC 4.0) license, which permits others to distribute, remix, adapt, build upon this work non-commercially, and license their derivative works on different terms, provided the original work is properly cited, appropriate credit is given, any changes made indicated, and the use is non-commercial. See: http://creativecommons.org/licenses/by-nc/4.0/.

ORCID iD

Chalapati Rao http://orcid.org/0000-0002-9554-0581

\section{REFERENCES}

1 GBD 2015 SDG Collaborators. Measuring the health-related sustainable development goals in 188 countries: a baseline analysis from the global burden of disease study 2015. Lancet 2016;388:1813-50.

2 Mahapatra P, Shibuya K, Lopez AD, et al. Civil registration systems and vital statistics: successes and missed opportunities. Lancet 2007;370:1653-63.

3 Mathers CD, Fat DM, Inoue M, et al. Counting the dead and what they died from: an assessment of the global status of cause of death data. Bull World Health Organ 2005;83:171-7.

4 Linder F. Vital event numeration system as a new tool for measuring population change. Bulletin of the International Statistical Institute 1971:44:377-93.

5 Linder FE, Moriyama IM. eds. Improving civil registration in developing countries. Bethesda, Maryland 20814 USA: international Institute for vital registration and statistics, 1984. Available: https:// www.cdc.gov/nchs/data/isp/020_improving_civil_registration_ system in developing countries.pdf

6 United Nations Statistics Division. Demographic and Social Statistics - Standards and Methods: Civil Registration and Vital Statistics New York: United Nations Statistics Division, 2019. Available: https:// unstats.un.org/unsd/demographic-social/Standards-and-Methods/ index.cshtml? search =\&Id=\&Desc $=$ Civil+Registration+and + Vital + Statistics\&Title=\&Year=\&topics $=$

7 National Center for Health Statistics. International Institute for vital registration and statistics reports: centers for disease control USA 2015. Available: https://www.cdc.gov/nchs/isp/isp iivrs.htm

8 Murray CJL, Lopez AD. The global burden of disease : a comprehensive assessment of mortality and disability from diseases, injuries, and risk factors in 1990 and projected to 2020. Cambridge, MA. USA: Published by the Harvard School of Public Health on behalf of the World Health Organization and the World Bank, 1996.

9 Murray CJL. Towards good practice for health statistics: lessons from the millennium development goal health indicators. Lancet 2007;369:862-73.

10 Mathers CD, Lopez AD, Stein C, et al. Deaths and disease burden by cause: global burden of disease estimates for 2001 by world bank country groups. Washington D.C: World Bank, World Health Organization, and Fogarty International Center, US National Institutes of Health, 2005. http://www.dcp2.org/file/33/wp18.pdf

11 Horton R. Counting for health. Lancet 2007;370.
12 World Health Organization. Verbal autopsy standards: ascertaining and attributing causes of death. Geneva: WHO, 2007. http://www. who.int/healthinfo/statistics/verbalautopsystandards/en/index3. html

13 World Bank | World Health Organization. Global civil registration and vital statistics: scaling up investment plan 2015-2024. Washington DC: health, nutrition and population team; 2014. Report No.: 88351. Available: http://documents.worldbank.org/curated/en/ 457271468148160984/pdf/883510WP0CRVS000Box385194B00 PUBLIC0.pdf

14 United Nations Statistics Division. Global civil registration and vital statistics group New York: United nations, 2014. Available: https:// unstats.un.org/unsd/demographic/crvs/globalcrvs.html

15 World Health Organization. Strengthening civil registration and vital statistics through innovative approaches in the health sector Geneva; 2014. Report No.: WHO/HIS/HSI/2014/1. Available: http:// www.who.int/healthinfo/civil registration/crvs meeting_dec2013 report.pdf?ua $=1$

16 United Nations Economic Commission for Africa. APAI-CRVS: Africa Programme for Accelerated Improvement of Civil Registration and Vital Statistics Addis Ababa. Ethiopia: UNECA, 2012. http://www. apai-crvs.org/about-apai

17 United Nations Economic Commission for Asia and Pacific (UNESCAP). Asian and Pacific civil registration and vital statistics decade 2015-2024. Bangkok: UNESCAP; 2015. Report No.: ST/ ESCAP/2717. Available: https://www.unescap.org/sites/default/ files/Asian_and_Pacific_Civil_Registration_and_Vital_Statistics Decade2015-2024 Booklet.pdf

18 Bloomberg Philanthropies. Data for health Initiative New York, 2015. Available: https://www.bloomberg.org/program/public-health/datahealth/\#overview

19 International Development Research Centre. Centre of Excellence for CRVS Systems Ottawa,Canada, 2016. Available: https:// crvssystems.ca/

20 World Health Organization. Improving the quality and use of birth, death and cause-of-death information: guidance for a standards-based review of country practices. Geneva: World Health Organization, 2010. Report No.: ISBN 9789241547970 (NLM classification: WA 900).

21 World Bank Group Open Learning Campus. Civil registration and vital statistics systems eLearning course: world bank group and Ministry of economics and finance, Republic of Korea, 2017. Available: https://olc.worldbank.org/content/civil-registration-andvital-statistics-systems-basic-level-self-paced-format

22 World Health Organization Regional Office for South East Asia. Regional strategy for strengthening the role of the health sector for improving CRVS (2015-2024). New Delhi: WHO SEARO, 2015. Available: http://www.searo.who.int/entity/health_situation_trends/ regional_strategy_for_strengthening_the_role_of_the_health_sector_ for_improving_crvs.pdf?ua=1

23 World Health Organization Regional Office for the Eastern Mediterranean. Regional strategy for the improvement of civil registration and vital statistics systems 2014-2019. Cairo; 2014 Report No.: WHO-EM/HST/216/E. Available: http://applications. emro.who.int/dsaf/EMROPUB_2014_EN_1754.pdf?ua=1

24 United Nations Economic and Social Commission for Asia and the Pacific. Regional action framework on civil registration and vita statistics in Asia and the Pacific. Bangkok, 2014. Available: https:// www.unescap.org/resources/regional-action-framework-civilregistration-and-vital-statistics-asia-and-pacific

25 United Nations Statistics Division, Cobos MI. Evaluation of the quality of civil registration and vital statistics systems. In: Mrkic S, Cobos Ml, eds. Handbook on Civil Registration and Vital Statistics Systems: Management, Operation and Maintenance - Revision 1. New York: Department of Economic and Social Affairs: United Nations Statistics Division, 2018: 72-101. https://unstats.un.org/ unsd/demographic-social/Standards-and-Methods/files/Handbooks/ crvs/crvs-mgt-E.pdf

26 World Health Organization. Thirteenth General programme of work 2019-2023: promote health, keep the world safe, serve the vulnerable. Geneva: World Health organization; 2019. Report No.: WHO/PRP/18.1. Available: https://apps.who.int/iris/bitstream/ handle/10665/324775/WHO-PRP-18.1-eng.pdf

27 Hill K, Lopez AD, Shibuya K, et al. Interim measures for meeting needs for health sector data: births, deaths, and causes of death Lancet 2007;370:1726-35.

28 United Nations Statistics Division. Principles and recommendations for a vital statistics system, revision 3. New York: department of social Affairs; 2014. Report No.: series M No. 19/Rev.3. Available: https://unstats.un.org/unsd/Demographic/standmeth/principles/ M19Rev3en.pdf 
29 World Health Organization. Mortality: guidelines for certification and rules for coding. International Statistical Classification of Diseases and Health Related Problems - Tenth Revision (ICD-10) Volume 2: Instruction Manual. 2. Geneva: World Health Organization, 1993: 30-65

30 World Health Organization. Who regional offices Geneva, 2019 Available: https://www.who.int/about/who-we-are/regional-offices

31 GBD. Cause of death Collaborators. Supplementary appendix 1: global, regional, and national age-sex speciic mortality for 264 causes of death, 1980-2016: a systematic analysis for the globa burden of disease study 2016. Lancet 2016;2017:1151-210.

32 Preston SH. Use of direct and indirect techniques for estimating the completeness of registration systems. Bangkok: United Nations, 1981. Report No.: ST/ESA/Series/A/84. https://www.popline.org/ node/400765

33 Naghavi M, Makela S, Foreman K, et al. Algorithms for enhancing public health utility of national causes-of-death data. Popul Health Metr 2010;8:9

34 França E, de Abreu DX, Rao C, et al. Evaluation of cause-of-death statistics for Brazil, 2002-2004. Int J Epidemiol 2008;37:891-901.

35 França E, Rao C, Abreu DMXde, et al. Comparison of crude and adjusted mortality rates from leading causes of death in northeastern Brazil. Rev Panam Salud Publica 2012;31:275-82.

36 Cobos Muñoz D, Abouzahr C, de Savigny D. The 'Ten CRVS Milestones' framework for understanding Civil Registration and Vital Statistics systems. BMJ Glob Health 2018;3:e000673.

37 Rao C, Bradshaw D, Mathers CD. Improving death registration and statistics in developing countries: lessons from SubSaharan Africa. South Afr J Demogr 2004;9:81-91.

38 Carter KL, Rao C, Lopez AD, et al. Mortality and cause-of-death reporting and analysis systems in seven Pacific Island countries. BMC Public Health 2012;12:436.

39 Rao C, Osterberger B, Anh TD, et al. Compiling mortality statistics from civil registration systems in Viet Nam: the long road ahead. Bull World Health Organ 2010;88:58-65.

40 Gupta M, Rao C, Lakshmi PVM, et al. Estimating mortality using data from civil registration: a cross-sectional study in India. Bull World Health Organ 2016;94:10-21.

41 Tangcharoensathien V, Faramnuayphol P, Teokul W, et al. A critical assessment of mortality statistics in Thailand: potential for improvements. Bull World Health Organ 2006;84:233-8.

42 Oung MT, Richter K, Prasartkul P, et al. Reliable mortality statistics in Myanmar: a qualitative assessment of challenges in two townships. BMC Public Health 2019;19:356.

43 Tin Oung M, Richter K, Prasartkul P, et al. Myanmar mortality registration: an assessment for system improvement. Popul Health Metr 2017;15:34.

44 World Health Organization. Verbal autopsy standards: ascertaining and attributing causes of death: the 2016. WHO verbal autopsy instrument: WHO, 2017. http://www.who.int/healthinfo/statistics/ verbalautopsystandards/en/

45 World Health Organization. Volume 1:Tabular List. International Statistical Classification of Diseases and Health Related Problems Tenth Revision (ICD-10). Geneva: World Health Organization, 1993

46 Rao C, Lopez AD, Yang G, et al. Evaluating national cause-of-death statistics: principles and application to the case of China. Bull World Health Organ 2005;83:618-25.

47 Joubert J, Rao C, Bradshaw D, et al. Evaluating the quality of national mortality statistics from civil registration in South Africa, 1997-2007. PLoS One 2013;8:e64592.

48 Hill K. Analytical Methods to Evaluate the Completeness and Quality of Death Registration: Current State of Knowledge. In Technical Paper Series: No. 2 - 2017. New York: Population Division: United Nations Department of Economic and Social Affairs, 2017: 1-31.

49 Salomon JA, Murray CJL. The epidemiologic transition revisited: compositional models for causes of death by age and sex. Popul Dev Rev 2002;28:205-28.

50 Rao C, Kelly M. Overview of the principles and international experiences in implementing record linkage mechanisms to assess completeness of death registration. In: Technical Paper Series: No. 5 - 2017. New York: Population Division: United Nations Department of Economic and Social Affairs, 2017: 1-54. http://www.un.org/en/ development/desa/population/publications/pdf/technical/TP2017-5. pdf

51 Prasartkul P, Vapattanawong P. The completeness of death registration in Thailand: evidence from demographic surveillance system of the Kanchanaburi project. World Health Popul 2006;8:43-51.

52 Rao C, Yang G, Hu J, et al. Validation of cause-of-death statistics in urban China. Int J Epidemiol 2007;36:642-51.
53 Omar A, Ganapathy SS, Anuar MFM, et al. Cause-specific mortality estimates for Malaysia in 2013: results from a national sample verification study using medical record review and verbal autopsy. BMC Public Health 2019;19:110.

54 Porapakkham Y, Rao C, Pattaraarchachai J, et al. Estimated causes of death in Thailand, 2005: implications for health policy. Popul Health Metr 2010;8:14

55 Sankoh O, Byass P. The indepth network: filling vital gaps in global epidemiology. Int J Epidemiol 2012;41:579-88.

56 Begg S, Rao C, Lopez AD. Design options for sample-based mortality surveillance. Int J Epidemiol 2005;34:1080-7.

57 Hoa NP, Rao C, Hoy DG, et al. Mortality measures from samplebased surveillance: evidence of the epidemiological transition in Viet Nam. Bull World Health Organ 2012;90:764-72.

58 Rao C, Kosen S, Bisara D, et al. Tuberculosis mortality differentials in Indonesia during 2007-2008: evidence for health policy and monitoring. Int J Tuberc Lung Dis 2011;15:1608-14.

59 Rao C, Soemantri S, Djaja S, et al. Mortality in central Java: results from the Indonesian mortality registration system strengthening project. BMC Res Notes 2010;3:325.

60 Yang G, Hu J, Rao KQ, et al. Mortality registration and surveillance in China: history, current situation and challenges. Popul Health Metr 2005;3:3.

61 Liu S, Wu X, Lopez AD, et al. An integrated national mortality surveillance system for death registration and mortality surveillance, China. Bull World Health Organ 2016;94:46-57.

62 Usman Y, Iriawan RW, Rosita T, et al. Indonesia's Sample Registration System in 2018: A Work in Progress. Journal of Population and Social Studies 2019;27:39-52.

63 Hill K, Vapattanawong P, Prasartkul P, et al. Epidemiologic transition interrupted: a reassessment of mortality trends in Thailand. Int $J$ Epidemiol 2006:1980-2000.

64 Rao C, Porapakkham Y, Pattaraarchachai J, et al. Verifying causes of death in Thailand: rationale and methods for empirical investigation. Popul Health Metr 2010;8:11.

65 Gaston V. Quality assessment of vital statistics: telling Canada's story in numbers. United nations expert group meeting on management and evaluation of CRVS systems. New York: United Nations, 2017. https://unstats.un.org/unsd/demographic-social/meetings/2017/ new-york--egm-on-management-and-evaluation-of-crvs-systems/ Session19-Canada-Validation.pdf

66 National Center for Health Statistics. NCHS fact sheet: national vital statistics system improvements. Atlanta, USA: centers for disease control and prevention, USA, 2019. Available: https://www.cdc.gov/ nchs/data/factsheets/factsheet-nvss-improvements-H.pdf

67 Rao C, Usman Y, Kelly M, et al. Building capacity for mortality statistics programs: perspectives from the Indonesian experience. $J$ Epidemiol Glob Health 2019;9:98-102.

68 Alderson MR, Bayliss RI, Clarke CA, et al. Death certification. $\mathrm{Br}$ Med J 1983;287:444-5.

69 Aung E, Rao C, Walker S. Teaching cause-of-death certification: lessons from international experience. Postgrad Med $\mathrm{J}$ 2010;86:143-52.

70 Nichols EK, Byass P, Chandramohan D, et al. The WHO 2016 verbal autopsy instrument: an international standard suitable for automated analysis by InterVA, InSilicoVA, and tariff 2.0. PLoS Med 2018;15:e1002486.

71 Padmanabha P. Review and evaluation report of UNFPA funded projects on civil registration and vital statistics. United Nations Population Fund, 1993. Available: http://unstats.un.org/unsd/ demographic/sources/civilreg/docs/Padmanabha\%20Paper.pdf

72 Vital registration systems in five developing countries: Honduras, Mexico, Philippines, Thailand, and Jamaica. Vital Health Stat 2 1980:1-159.

73 De Guzman ET. Quality assessment of the Philippines civil registration and vital statistics system. United nations expert group meeting on management and evaluation of CRVS systems. New York: United Nations, 2017. https://unstats.un. org/unsd/demographic-social/meetings/2017/new-york--egmon-management-and-evaluation-of-crvs-systems/Session18Philippines-Quality-Assessment.pdf

74 Özdemir R, Rao C, Öcek Z, et al. Reliable mortality statistics for Turkey: are we there yet? BMC Public Health 2015;15:545.

75 Al-Muzahmi SNK. Mortality patterns in Oman: Demographic and Epidemiological Review [PhD thesis]. Brisbane, Australia: University of Queensland, 2015. https://espace.library.uq.edu.au/view/UQ: 369205

76 National Organization for Civil Registration. An introduction to the civil registration system in the Islamic Republic of Iran. Sub regional workshop for implementing the regional action framework for CRVS in Asia. Istanbul, Turkey: United Nations, 2015. https://unstats. 
